\title{
Heart Rate Variability in Extremely Preterm Infants Receiving Nasal CPAP and Non-Synchronized Noninvasive Ventilation Immediately After Extubation
}

\author{
Samantha Latremouille MSc, Ali Al-Jabri MD, Philippe Lamer NNP, Lara Kanbar MSc, \\ Wissam Shalish MD, Robert E Kearney PhD, and Guilherme M Sant'Anna MD PhD
}

\begin{abstract}
INTRODUCTION: There is a paucity of studies comparing the physiological effects of nasal CPAP or non-synchronized noninvasive ventilation (ns-NIV) during the postextubation phase in preterm infants. Heart rate variability (HRV) can identify system instability before clinical or laboratory signs of deterioration. Thus, we sought to investigate any differences in HRV between those modes. METHODS: 15 preterm infants with birthweight $\leq 1,250 \mathrm{~g}$ and undergoing their first extubation attempt were studied immediately after disconnection from mechanical ventilation. Electrocardiogram (ECG) recordings were obtained while on nasal CPAP and ns-NIV in a random order (30-60 min on each). Time and frequency domain analyses were used to calculate HRV from 5-min segments of ECG. RESULTS: 12 of 15 infants were analyzed (3 were excluded for low ECG quality): 7 successes and 5 failures. HRV parameters were higher during ns-NIV when compared to nasal CPAP, but differences were not statistically different. However, absolute and relative differences in HRV values (all time domain parameters) were significantly higher in infants who failed extubation during ns-NIV. CONCLUSIONS: Nasal CPAP or ns-NIV provided immediately postextubation did not affect HRV. Interestingly, in an exploratory analysis, changes in HRV did occur during ns-NIV in the subgroup of infants who failed extubation. Hence, changes in HRV as early as $\mathbf{2} \mathbf{h}$ after extubation should be further explored in larger studies as a potential predictor of postextubation respiratory failure. Key words: extubation failure; heart rate variability; noninvasive ventilation; preterm infants; respiratory support; neonatal intensive care. [Respir Care 2018;63(1):62-69.

(c) 2018 Daedalus Enterprises]
\end{abstract}

\section{Introduction}

The majority of extremely preterm infants require intubation and mechanical ventilation after birth. ${ }^{1-3}$ Because

\footnotetext{
Drs Shalish and Sant'Anna, as well as Ms Latremouille and Mr Lamer, are affiliated with the Division of Neonatology, Department of Pediatrics, McGill University Health Center, Montreal, Canada. At the time of this study, Dr Al-Jabri was also affiliated with the Division of Neonatology, Department of Pediatrics, McGill University Health Center, Montreal, Canada. Dr Kearney and Ms Kanbar are affiliated with the Department of Biomedical Engineering, Duff Medical Building, McGill University, Montreal, Canada.
}

Ms Latremouille presented a version of this paper at the American Thoracic Society International Conference, held May 13-18, 2016, in San Francisco, California.

The authors have disclosed no conflicts of interest. mechanical ventilation can lead to complications, ${ }^{4,5}$ physicians often proceed from early extubation to some type of noninvasive respiratory support, ${ }^{6}$ most commonly nasal CPAP and noninvasive ventilation (NIV). ${ }^{6,7}$ In a recent meta-analysis comparing these 2 modes, NIV demonstrated superiority over nasal CPAP in preventing extubation failure. ${ }^{8}$ However, the pooled studies were very heteroge-

\footnotetext{
Supplementary material related to this paper is available at http:// www.rcjournal.com.

Correspondence: Guilherme Sant'Anna MD PhD, Associate Professor of Pediatrics, Neonatal Division, McGill University Health Center, 1001 Boulevard Decarie, Room B05.2711, Montreal, Quebec, Canada, H4A3J1. E-mail: guilherme.santanna@mcgill.ca.
}

DOI: $10.4187 /$ respcare. 05672 


\section{HRV AND RESPIRATORy SuPPORT IN PRETERm Infants}

neous and used different nasal CPAP and NIV modalities, making it difficult to translate these results into clinical practice. From the available evidence, synchronization during NIV appears to confer important clinical and physiological benefits in the immediate postextubation period. In contrast, the mechanisms of action of non-synchronized NIV (ns-NIV) are not yet fully understood. ${ }^{8}$ To date, the only physiological study comparing nasal CPAP with nsNIV found no differences in tidal volume, minute ventilation, breathing frequency, gas exchange, or inspiratory effort among clinically stable infants studied $1 \mathrm{wk}$ after extubation. ${ }^{9}$

Heart rate variability (HRV) refers to the fluctuations of beat-to-beat intervals over time. ${ }^{10}$ In neonates, HRV measurements identified system instability before clinical or laboratory signs of deterioration, as demonstrated for the prediction of sepsis, ${ }^{11}$ weaning from mechanical ventilation, ${ }^{12}$ and outcomes of hypoxic-ischemic encephalopathy. ${ }^{13,14}$ Therefore, we hypothesized that during the unstable period after extubation, any additional benefit of ns-NIV over nasal CPAP would be reflected by differences in HRV. As a secondary exploratory analysis, differences in HRV and extubation outcomes were evaluated.

\section{Methods}

\section{Population}

This prospective randomized crossover trial was conducted in 3 neonatal intensive care units (Royal Victoria Hospital, Montreal Children's Hospital and Jewish General Hospital, Montreal, Canada). Subjects with birthweight $\leq 1,250 \mathrm{~g}$, receiving mechanical ventilation, and undergoing their first extubation attempt were eligible. Infants with congenital anomalies or receiving narcotics, sedatives, or inotropes at the time of extubation were excluded. The research ethics board of each institution approved the study, and informed consent was obtained from parents or legal guardians. This study received financial support from the Royal Victoria Foundation.

\section{Peri-extubation Management}

Clinical decisions concerning intubation, adjustments, and weaning of mechanical ventilation, timing of extubation, type of postextubation respiratory support provided outside of the study period, and the need for re-intubation were made exclusively by the treating physician. The current practice of the units was to keep oxygen saturation $\left(\mathrm{S}_{\mathrm{pO}_{2}}\right)$ alarms between $85-94 \%$ (target: 88-92\%).

\section{Study Design and Data Acquisition}

Before extubation, 3 electrocardiogram (ECG) leads were placed on the infants' limbs, at least $1 \mathrm{~cm}$ apart from

\section{QUICK LOOK}

\section{Current knowledge}

Extubation failure rates are high in extremely preterm infants. To increase the chances of successful extubation, noninvasive respiratory support such as nasal CPAP or ns-NIV are applied immediately after extubation. Heart rate variability is a useful marker of wellbeing and may provide insight on differences between those modes.

\section{What this paper contributes to our knowledge}

The study provides new information on the physiological effects of nasal CPAP or ns-NIV in extremely preterm infants immediately after extubation. Heart rate variability was not affected by either mode. An exploratory analysis showed that changes on heart rate variability during ns-NIV occurred only in infants who failed extubation.

the existing leads to prevent interference. After extubation, a period of $30 \mathrm{~min}$ was allowed for rest and stabilization free of any unnecessary manipulations prior to initiation of recordings. During this transition period, infants received the type of noninvasive respiratory support determined by the treating team, either nasal CPAP or ns-NIV. Throughout the study, infants were kept in a supine position, and all efforts were made to minimize leaks by using the appropriate size of binasal prongs (Hudson RCI, Wayne, Pennsylvania) and applying the Cannulaide (Salter Labs, Lake Forest, Illinois) and a chinstrap. Nasal CPAP or nsNIV was provided in a random order, and oxygen supplementation was adjusted to maintain $\mathrm{S}_{\mathrm{pO}_{2}}$ within the target range. Nasal CPAP or PEEP levels were set at 5 or $6 \mathrm{~cm} \mathrm{H}_{2} \mathrm{O}$ (depending on the pre-extubation PEEP level), and inflation pressures during ns-NIV were set $10 \mathrm{~cm} \mathrm{H}_{2} \mathrm{O}$ above the PEEP. ECG was recorded for a period of 30-60 min for each mode using a bioamplifier (FE132, ADInstruments, Colorado Springs, Colorado) connected to the PowerLab acquisition system (ADInstruments), and signals were stored in a research computer for analysis. Recordings on each mode included an initial 10-min washout period. A timeline for the study design is provided in Figure 1.

\section{Heart Rate Variability}

HRV analysis was performed offline using the HRV module of the LabChart software (version 1.4.2, ADInstruments). The following definitions were used for the normal-tonormal beat $(\mathrm{NN})$ intervals: normal $=300-600 \mathrm{~ms}(100-200$ beats/min), ectopics $=200-300 \mathrm{~ms}(200-300$ beats $/ \mathrm{min})$ 


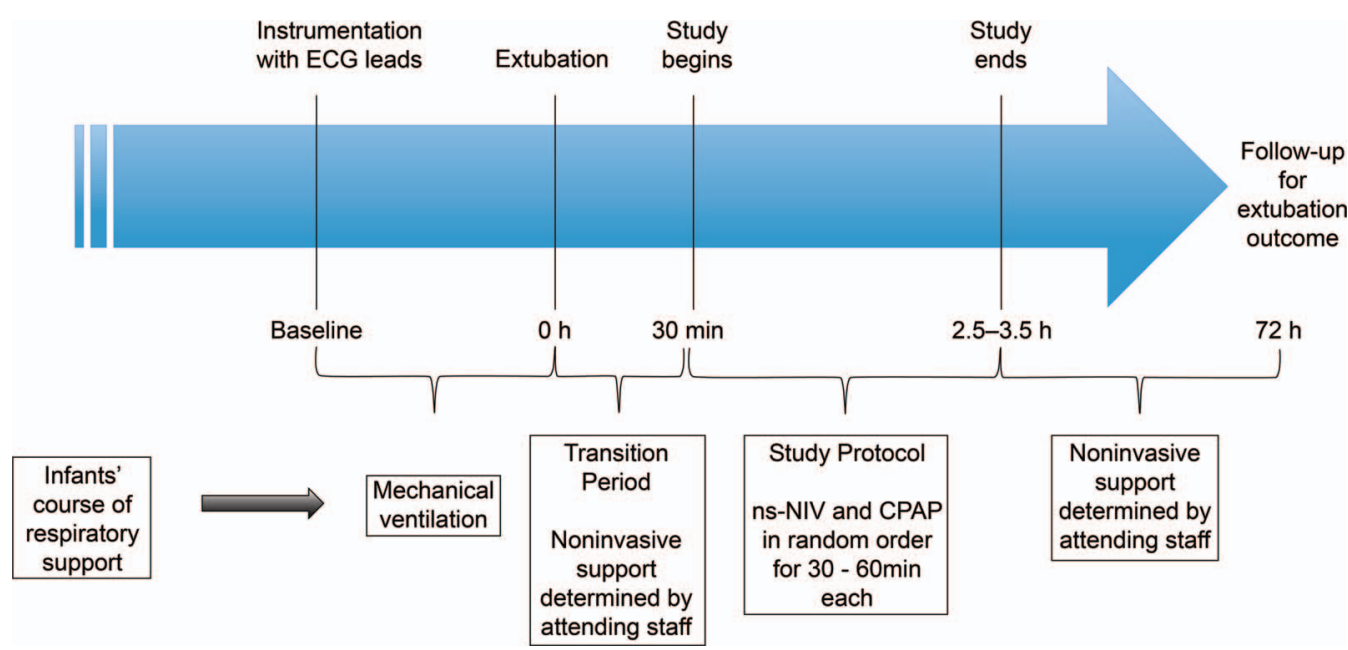

Fig. 1. Study timeline. Baseline $=1 \mathrm{~h}$ before extubation (mechanically ventilated with echocardiogram leads). 30 min postextubation $=$ study recordings begin with mode of noninvasive support in random order. $72 \mathrm{~h}$ postextubation $=$ determine outcome (success or failure). ECG electrocardiogram; NIV = noninvasive ventilation; ns-NIV = non-synchronized NIV.

and $600-1000(60-100$ beats $/ \mathrm{min})$, and artifacts $=<200 \mathrm{~ms}$ ( $>300$ beats/min) and $>1,000 \mathrm{~ms}(<60$ beats/min). Each selected ECG segment required manual adjustments of the voltage thresholds to maximize beat detection. The first $10 \mathrm{~min}$ of ECG recording on nasal CPAP or ns-NIV was considered a transitional washout period and was not included in the analysis. The first acceptable 5-min segment with $\leq 80 \%$ normal NN intervals, starting from the end of each mode (or the last segment) was selected. A band-pass filter of $5-80 \mathrm{~Hz}$ was applied to each segment prior to analysis to reduce noise. The following time domain parameters were calculated: standard deviation of the $\mathrm{NN}$ intervals (SDNN), that is, the variation of intervals measured between consecutive sinus beats, standard deviation of the successive differences between NN intervals (SD delta NN), root mean square of successive differences of NN intervals (RMSSD), and the percentage of adjacent NN intervals that differ by $>50 \mathrm{~ms}$ (pNN50). For the frequency domain, the following parameters were obtained: TP: total power $(<0.4 \mathrm{~Hz})$, VLF: very low frequency $(<0.04 \mathrm{~Hz})$, LF: low frequency $(0.04-0.15 \mathrm{~Hz})$, HF: high frequency $(>0.15$ to $<0.4 \mathrm{~Hz})$, and $\mathrm{LF} / \mathrm{HF}$ : ratio of the low-frequency to high-frequency power. ${ }^{10}$

\section{Clinical Data}

Baseline subject demographics (birthweight, gestational age, sex, Apgar scores along with weight, day of life, and post-conceptional age at extubation), pre-extubation blood gases ( $\mathrm{pH}, \mathrm{P}_{\mathrm{CO}_{2}}$, bicarbonate, and base excess), ventilation settings (mode, peak inspiratory pressure [PIP], PEEP, mean airway pressure $\left(\overline{\mathrm{P}}_{\mathrm{aw}}\right)$, breathing frequency, $\mathrm{F}_{\mathrm{IO}_{2}}$, and $\mathrm{S}_{\mathrm{pO}_{2}}$ ), noninvasive respiratory support used during the transition period (mode, PIP, PEEP, and inflation rates), use of caffeine and postnatal steroids at the time of extu- bation, and extubation outcomes (success or failure) were prospectively collected. Extubation failure was defined as the need for re-intubation within 72 h. ${ }^{6,15}$ The primary reason for re-intubation (apneas and bradycardias, increased work of breathing, respiratory acidosis) was also recorded.

The primary objective of the study was to investigate for differences in HRV parameters between nasal CPAP and ns-NIV. As a secondary objective, HRV parameters were related to extubation outcomes, with the rationale that successfully extubated infants may have a different underlying physiology compared to infants who fail extubation. As such, the following comparisons were made:

1) For each of the success and failure groups, HRV parameters were compared between nasal CPAP and nsNIV.

2) For each of the nasal CPAP and ns-NIV groups, HRV parameters were compared between success and failure.

3) The absolute and relative changes in HRV values from one mode to the other $(\Delta \mathrm{HRV}$ and percentage $\Delta \mathrm{HRV}$, respectively) were compared between the success and failure groups. $\triangle \mathrm{HRV}$ was calculated as the HRV values while on ns-NIV minus nasal CPAP, and percentage $\triangle \mathrm{HRV}$ was calculated as $\triangle \mathrm{HRV}$ divided by the nasal CPAP values multiplied by 100 .

\section{Sample Size and Statistical Analysis}

Given the lack of data on HRV in preterm infants during the immediate postextubation period, a calculation of sample size was not possible. Therefore, a convenience sample size of 12 infants was chosen. On the basis of our previous experience, due to the low quality of ECG signals detected during the offline analysis, a loss between $10-20 \%$ of the subjects was expected. ${ }^{12}$ Thus, we planned to enroll 15 
Table 1. Subject Characteristics and Pre-extubation Management

\begin{tabular}{|c|c|c|c|c|}
\hline & All Subjects $(N=12)$ & Success $(N=7)$ & Failure $(N=5)$ & $P$ \\
\hline \multicolumn{5}{|l|}{ Characteristics } \\
\hline Birth weight, $g$ & $855[746-1013]$ & $890[778-1015]$ & $760[750-920]$ & .64 \\
\hline Gestational age, wk & $27.0[25.3-28.0]$ & $28.0[26.3-28.1]$ & $25.3[25.0-26.6]$ & .068 \\
\hline Male & $6(50)$ & $3(42.9)$ & $3(60)$ & $>.99$ \\
\hline 5-min Apgar & $7[6-7]$ & $7[6-7]$ & $7[6-8]$ & .78 \\
\hline Weight at extubation, $\mathrm{g}$ & $895[725-983]$ & $970[835-985]$ & $820[645-850]$ & .27 \\
\hline Age at extubation, $\mathrm{d}$ & $3.3[1.3-5.5]$ & $2[1.2-4.4]$ & $3.3[3.2-7.0]$ & .67 \\
\hline Post-conceptional age at extubation, wk & $27.6[25.9-28.2]$ & $28.1[27.0-29.0]$ & $26.2[25.6-27.6]$ & .10 \\
\hline \multicolumn{5}{|l|}{ Pre-extubation } \\
\hline Mode: continuous mandatory ventilation & $5(42)$ & $1(14)$ & $4(80)$ & .07 \\
\hline SIMV & $7(58)$ & $6(86)$ & $1(20)$ & \\
\hline PIP, $\mathrm{cm} \mathrm{H}_{2} \mathrm{O}$ & $13[12-14]$ & $12[10-13]$ & $13[13-14]$ & .17 \\
\hline PEEP, $\mathrm{cm} \mathrm{H}_{2} \mathrm{O}$ & $5[4-5]$ & $4[4-5]$ & $5[5-5]$ & .038 \\
\hline$\overline{\mathrm{P}}_{\mathrm{aw}}, \mathrm{cm} \mathrm{H}_{2} \mathrm{O}$ & $6.8[5.9-8.1]$ & $6.0[5.4-6.3]$ & $8.0[7.0-8.5]$ & .043 \\
\hline $\mathrm{F}_{\mathrm{IO}_{2}}$ & $0.23[0.21-0.28]$ & $0.21[0.21-0.27]$ & $0.25[0.21-0.30]$ & .47 \\
\hline Frequency, breaths/min & $28[20-33]$ & $25[20-30]$ & $30[20-40]$ & .76 \\
\hline Oxygen saturation, $\%$ & $94[93-96][n=11]$ & $95[91-96][n=6]$ & 94 [94-94] & $>.99$ \\
\hline Caffeine & $9(75)$ & $5(71)$ & $4(80)$ & $>.99$ \\
\hline Postnatal steroids & $2(17)$ & $1(14)$ & $1(20)$ & $>.99$ \\
\hline \multicolumn{5}{|l|}{ Blood gas pre-extubation } \\
\hline $\mathrm{pH}$ & $7.29[7.26-7.34]$ & $7.29[7.29-7.35]$ & $7.26[7.25-7.28]$ & .24 \\
\hline $\mathrm{P}_{\mathrm{CO}_{2}}$ & $53[42-55]$ & $42[41-54]$ & $54[54-55]$ & .25 \\
\hline Bicarbonate, $\mathrm{mmol} / \mathrm{L}$ & $23[22-25]$ & $23[21-24]$ & $25[23-26]$ & .22 \\
\hline Base excess & $-2.4[-3.6--0.7]$ & $-2.4[-5.1--2.1]$ & $-0.7[-3.0--0.5]$ & .34 \\
\hline $\begin{array}{l}\text { Values expressed as median }[\mathrm{IQR}] \text { or } n(\%) . P \text { value: Succ } \\
\text { SIMV = synchronized intermittent mandatory ventilation } \\
\mathrm{PIP}=\text { peak inspiratory pressure } \\
\overline{\mathrm{P}}_{\mathrm{aw}}=\text { mean airway pressure } \\
\mathrm{P}_{\mathrm{CO}_{2}}=\text { arterial partial pressure of } \mathrm{CO}_{2}\end{array}$ & ilure groups. & & & \\
\hline
\end{tabular}

subjects. Continuous and categorical clinical variables were compared using the non-parametric two-sided Wilcoxon rank-sum test or Fisher exact test, respectively (Matlab, MathWorks Inc., Massachusetts). Paired Wilcoxon signedrank tests were used for all comparisons between nasal CPAP and ns-NIV, while Wilcoxon rank-sum tests were used for all comparisons between success and failure groups. Statistical significance was set at $P<.05$.

\section{Results}

A total of 15 subjects were studied; 3 subjects were excluded due to low-quality ECG ( 2 were successfully extubated and 1 failed extubation). Of the 12 subjects included, 7 were successfully extubation and 5 failed extubation. Subject demographics, respiratory support settings pre- and postextubation, blood gas results, and postextubation management are described in Tables 1 and 2. Infants who failed extubation were extubated from significantly higher $\overline{\mathrm{P}}_{\text {aw }}$ (8 vs $6 \mathrm{~cm} \mathrm{H}_{2} \mathrm{O}, P=.043$ ). After the study protocol, 1 infant in the success group was switched from ns-NIV to nasal CPAP, while 2 infants in the failure group that were originally receiving nasal CPAP were switched over to ns-NIV (Table 2).

\section{Primary Outcome}

All HRV parameters, for both time and frequency domain, were higher during ns-NIV compared to nasal CPAP, but the differences were not statistically significant (Table 3).

\section{Exploratory Analysis}

There were no differences on all absolute HRV values between nasal CPAP and ns-NIV for both groups (ie, extubation success and failure). Analysis comparing infants who were successfully extubated or failed extubation showed that, during ns-NIV, a higher SDNN was observed in failure subjects (23.9 ms [20.3-25.1]) versus $14.7 \mathrm{~ms}$ [11.8-16.4], respectively, $P<.05$ ). Finally, $\Delta \mathrm{HRV}$ and $\%$ $\Delta \mathrm{HRV}$ values were significantly higher in the failure group for all time domain parameters (Fig. 2). The $\Delta \mathrm{HRV}$ values were also significantly higher in the failure group for the 
Table 2. Postextubation Management

\begin{tabular}{|c|c|c|c|c|}
\hline & All Subjects $(N=12)$ & Success $(n=7)$ & Failure $(n=5)$ & $P$ \\
\hline \multicolumn{5}{|l|}{ Pre-study } \\
\hline Mode: ns-NIV & $9(75)$ & $6(86)$ & $3(60)$ & .52 \\
\hline Nasal CPAP & $3(25)$ & $1(14)$ & $2(40)$ & \\
\hline PIP, $\mathrm{cm} \mathrm{H}_{2} \mathrm{O}$ & $15[14-15]$ & $14[13-15]$ & $15[15-16]$ & .26 \\
\hline PEEP or CPAP level, $\mathrm{cm} \mathrm{H}_{2} \mathrm{O}$ & $5[5-5]$ & $5[5-5]$ & $5[5-6]$ & .52 \\
\hline Frequency, breaths/min & $20[20-30]$ & $25[20-38]$ & $20[18-25]$ & .43 \\
\hline \multicolumn{5}{|l|}{ Post-study } \\
\hline Mode: ns-NIV & $10(83)$ & $5(71)$ & $5(100)$ & .47 \\
\hline Nasal CPAP & $2(17)$ & $2(29)$ & $0(0)$ & \\
\hline PIP, $\mathrm{cm} \mathrm{H}_{2} \mathrm{O}$ & $15[14-16]$ & $14[12-14]$ & $15[15-16]$ & .09 \\
\hline PEEP or CPAP level, $\mathrm{cm} \mathrm{H}_{2} \mathrm{O}$ & $5[5-5]$ & $5[5-5]$ & $5[5-5]$ & .64 \\
\hline Frequency, breaths/min & $20[20-30]$ & $20[20-40]$ & $20[20-30]$ & .52 \\
\hline \multicolumn{5}{|l|}{ Time of re-intubation } \\
\hline $12-24 \mathrm{~h}$ postextubation & NA & NA & $4(80)$ & NA \\
\hline $24-48 \mathrm{~h}$ postextubation & NA & NA & $1(20)$ & NA \\
\hline \multicolumn{5}{|l|}{ Reasons for re-intubation } \\
\hline Respiratory acidosis & NA & NA & $1(20)$ & NA \\
\hline Increased work of breathing & NA & NA & $1(20)$ & NA \\
\hline Apneas and bradycardias & NA & NA & $3(60)$ & NA \\
\hline \multicolumn{5}{|c|}{$\begin{array}{l}\text { Values are expressed as median }[\mathrm{IQR}] \text { or } n(\%) . P \text { value: Success vs Failure groups. } \\
\text { ns-NIV = non-synchronized noninvasive ventilation } \\
\text { PIP = peak inspiratory pressure } \\
\text { NA = not available }\end{array}$} \\
\hline
\end{tabular}

Table 3. Comparison of Heart Rate Variability Parameters Between Nasal CPAP and ns-NIV

\begin{tabular}{|c|c|c|c|}
\hline $\begin{array}{c}\text { Heart Rate Variability } \\
\text { Parameter }\end{array}$ & Nasal CPAP & ns-NIV & $P$ \\
\hline \multicolumn{4}{|l|}{ Time domain analysis } \\
\hline SDNN, ms & $12.2[7.3-23.1]$ & $18.4[14.7-21.2]$ & .38 \\
\hline SD delta NN, ms & $7.4[3.8-18.9]$ & $14.5[8.0-24.9]$ & .79 \\
\hline RMSSD, ms & $7.4[3.8-18.8]$ & $14.5[8.0-24.8]$ & .79 \\
\hline pNN50, \% & $0.5[0-0.7]$ & $0.5[0.2-2.3]$ & .52 \\
\hline \multicolumn{4}{|l|}{$\begin{array}{l}\text { Frequency domain } \\
\text { analysis }\end{array}$} \\
\hline $\mathrm{TP}, \mathrm{ms}^{2}$ & $143.8[29.6-646.6]$ & $240.1[128.6-623.0]$ & .57 \\
\hline VLF, $\mathrm{ms}^{2}$ & $39.8[22.3-208.4]$ & $126.8[63.0-334.5]$ & .11 \\
\hline $\mathrm{LF}, \mathrm{ms}^{2}$ & $33.9[3.6-123.6]$ & $49.4[34.8-143.0]$ & .68 \\
\hline $\mathrm{HF}, \mathrm{ms}^{2}$ & $24.5[2.4-95.8]$ & $41.4[8.5-60.0]$ & .62 \\
\hline $\mathrm{LF} / \mathrm{HF}$, ratio & $1.7[0.6-5.6]$ & $3.2[0.8-6.9]$ & .73 \\
\hline $\begin{array}{l}\text { Values expressed as median } \\
\text { nasal CPAP and ns-NIV. } \\
\text { ns-NIV = non-synchronized n } \\
\text { SDNN = SD of NN intervals } \\
\text { SD delta NN = SD of the suc } \\
\text { RMSSD = root mean square } \\
\text { pNN50 = percentage of adjace } \\
\text { TP = total power }(<0.4 \mathrm{~Hz}) \\
\mathrm{VLF}=\text { very low frequency } \\
\mathrm{LF}=\text { low frequency }(0.04-0.1 \\
\mathrm{HF}=\text { high frequency }(>0.15 \\
\mathrm{LF} / \mathrm{HF} \text { ratio = ratio of the low }\end{array}$ & $\begin{array}{l}\mathrm{QR}] \text {. Heart rate variability re } \\
\text { ninvasive ventilation } \\
\text { essive differences between } \\
\mathrm{f} \text { successive differences of } \\
\text { nt } \mathrm{NN} \text { intervals that differ b } \\
0.04 \mathrm{~Hz} \text { ) } \\
5 \mathrm{~Hz}) \\
\text { to }<0.4 \mathrm{~Hz} \text { ) } \\
\text {-frequency to high-frequency }\end{array}$ & sults for all 12 subjects recei & \\
\hline
\end{tabular}

TP and VLF components of the frequency domain (see the supplementary materials at http://www.rcjournal.com).

\section{Discussion}

This prospective crossover observational study provides new information on the physiological effects of ns-NIV in extremely preterm infants undergoing their first extubation attempt. HRV values were higher on ns-NIV compared to nasal CPAP, but differences were not statistically significant. Interestingly, in the exploratory analysis, higher absolute and relative changes in HRV values were observed in infants who failed extubation. Results of this study are unique given the challenges of studying extremely preterm infants during the period immediately after extubation. Furthermore, results of the secondary analysis raise the possibility that HRV measurements may be useful for early identification of infants at high risk of postextubation failure.

\section{Nasal CPAP Versus Non-Synchronized NIV}

NIV use has increased as a result of evidence from randomized control trials and a recent meta-analysis ${ }^{8}$ suggesting improved extubation outcomes compared to nasal CPAP. It is interestingly that most beneficial effects were reported in studies that applied synchronized NIV. ${ }^{8}$ In- 


\section{HRV AND RESPIRATORY SUPPORT IN PRETERM INFANTS}
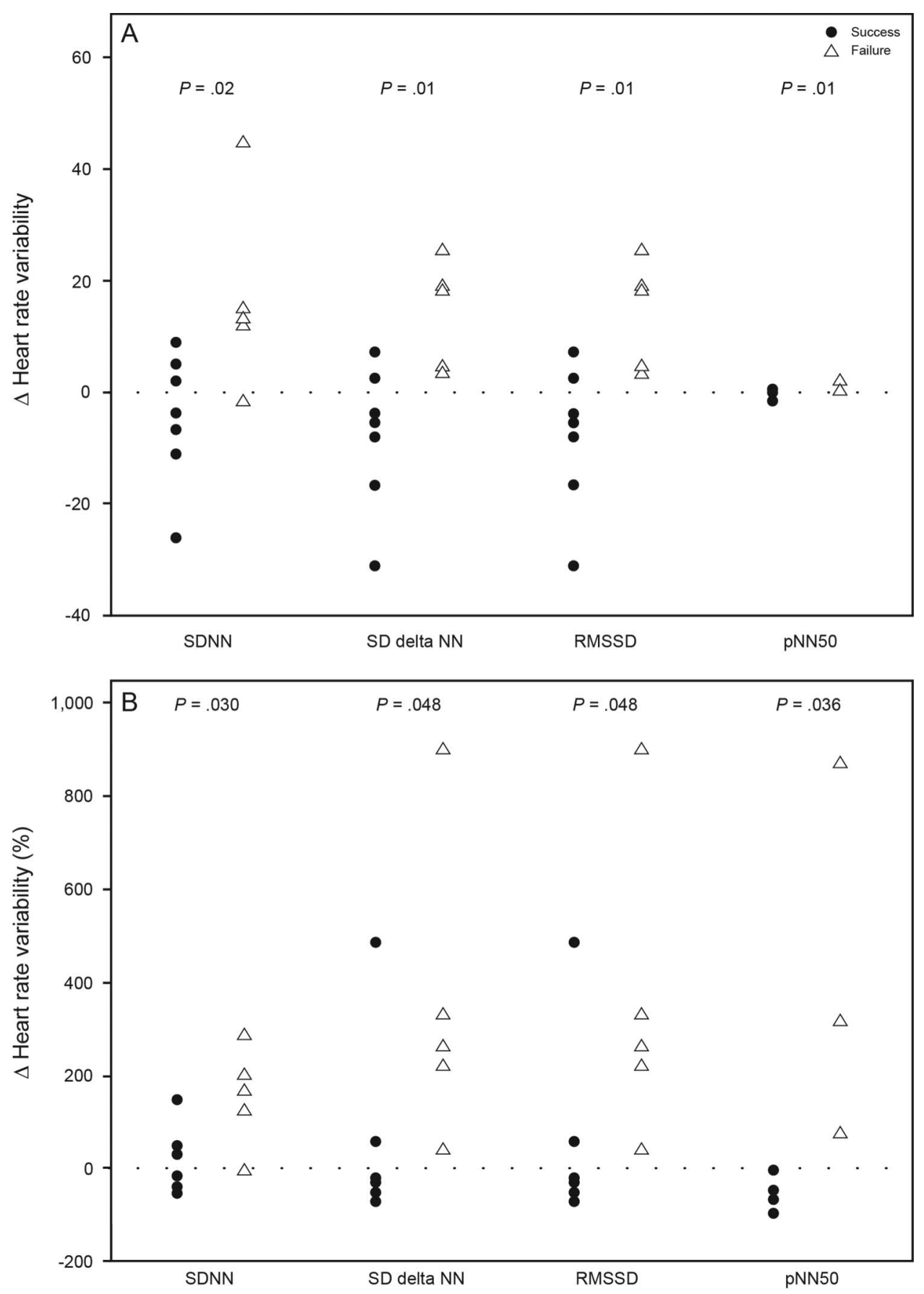

Fig. 2. Changes in heart rate variability and extubation outcomes. Changes in heart rate variability values were significantly higher in the failure group than the success group for all time domain parameters. $A=$ Absolute changes in heart rate variability. $B=P e r c e n t a g e$ change in heart rate variability. SDNN = standard deviation of NN intervals; SD delta NN = standard deviation of the successive differences between NN intervals; RMSSD = root mean square of successive differences of NN intervals; pNN50 = percentage of adjacent NN intervals that differ by $>50 \mathrm{~ms}$.

deed, in preterm infants evaluated immediately postextubation, synchronization during NIV was demonstrated to improve tidal volume, minute ventilation, gas exchange, and thoracoabdominal synchrony while reducing breathing frequency and inspiratory effort. ${ }^{16,17}$ Such beneficial effects have not been reported with ns-NIV, ${ }^{9}$ and the largest trial evaluating this mode did not show any differences in important clinical outcomes. ${ }^{18}$

HRV has been shown to be an accurate biomarker of wellbeing, able to detect changes in response to both phys- 


\section{HRV AND RESPIRATORy SuPPORT IN PRETERm Infants}

iological and non-physiological events. ${ }^{19}$ In adults, natural $\mathrm{R}-\mathrm{R}$ interval oscillations occur due to small changes in intrathoracic pressure during normal respiration, and the addition of positive airway pressure has been shown to further modulate HRV. ${ }^{20}$ Thus, one could hypothesize that, in preterm infants, the application of higher mean airway pressures with ns-NIV would also alter intrathoracic pressure and modulate HRV. ${ }^{21-23}$ However, transmission of positive pressure to the lungs may not always be reliable, and HRV behavior may vary according to patient stability. In a study evaluating stable preterm infants, ns-NIV was associated with highly variable PIP levels around the set value, ${ }^{24}$ depending on the timing of inflation in relation to each spontaneous inspiration, presence of leaks, or an apneic event. ${ }^{25}$ Furthermore, in a newborn lamb model, increased activity of the thyroarytenoid muscle (glottal constriction) was noted during the inspiratory phase of a breath delivered during ns-NIV but not during nasal CPAP. Higher PIP levels were associated with increased thyroarytenoid activity and occasionally caused complete glottal closure, thereby impeding pressure transmission and lung ventilation. ${ }^{26}$ Finally, another study in stable preterm infants revealed no significant differences in cardiac function and cerebral hemodynamics between nasal CPAP and ns-NIV. ${ }^{27}$

Our study is the first to investigate the effects of ns-NIV and nasal CPAP on HRV during the immediate postextubation phase. Although an increased level of support resulting from ns-NIV would have theoretically influenced HRV parameters, no statistically significant changes were observed. It is plausible that this was related to the absence of adequate subject-ventilator interaction during ns-NIV.

\section{HRV and Extubation Outcome}

Failure of noninvasive respiratory support applied after extubation is highly prevalent in extremely preterm infants. ${ }^{7}$ Despite clinical and laboratory similarities, some infants are successfully extubated while others fail extubation. No good predictor of extubation outcome is currently available. ${ }^{28} \mathrm{HRV}$ is a highly sensitive tool capable of detecting various stressors and distinguishing between different disease states. ${ }^{19}$ As such, changes in HRV can reflect intentionally generated responses to internal and external stimuli rather than simple random fluctuations. As an example, application of positive distending pressure resulted in significant HRV changes in subjects with COPD but caused no changes in healthy controls. ${ }^{23}$ A similar phenomenon was observed in our exploratory analysis, whereby changes between nasal CPAP and ns-NIV did not affect HRV in successfully extubated infants, but such changes caused significantly higher absolute $(\Delta \mathrm{HRV})$ and relative changes ( $\% \Delta \mathrm{HRV})$ for almost all HRV parameters in the failure group. We speculate that such changes could indicate a beneficial modulating effect of ns-NIV on the autonomic nervous system of more unstable infants. Another possible explanation is that infants who failed extubation were 2 weeks more immature than successfully extubated subjects. However, evidence from longitudinal studies suggests a very slow maturation process of the autonomic nervous system around 24 to 28 weeks postconceptional age, ${ }^{29,30}$ therefore such maturational difference cannot explain the significantly increased $\triangle \mathrm{HRV}$ parameters observed in the failure group. Alternatively, the differences observed could be related to a discomfort associated with the use of higher $\overline{\mathrm{P}}_{\mathrm{aw}}$ or the absence of synchronization in the more unstable infants. Nevertheless, while the increased benefit of one mode over the other remains unclear, significant changes in HRV measurements were observed and can be explored in future studies as a potential predictor of respiratory failure, as early as $2 \mathrm{~h}$ after extubation. With the introduction of new technologies able to continuously measure HRV at the bedside, prompt identification of infants at high risk of failure could lead to implementation of interventions with the potential to change this undesirable outcome.

This study has several strengths. We used a crossover methodology in random order, which prevents any one mode from influencing the other and the subject acts as his or her own control. ECG and clinical data were prospectively collected and analyzed by a group of researchers familiar with the methodology applied. Given the small numbers for comparison, the analysis of differences between success and failure was solely exploratory and hypothesis-generating. Frequency domain ranges were set according to the guidelines of the Task Force of The European Society of Cardiology and The North American Society of Pacing and Electrophysiology, ${ }^{10}$ as they are the only standardized ranges that currently exist. Although the ranges are for adults, to our knowledge respiratory sinus arrhythmia has not been demonstrated in infants with gestational age $<30$ wks. ${ }^{31}$ In addition, ECG recordings were made for relatively short durations $(30-60 \mathrm{~min})$. It is unclear whether the HRV results would have changed with longer exposure times.

\section{Conclusion}

Nasal CPAP or ns-NIV, the two most commonly used modes of noninvasive respiratory support provided to extremely preterm infants immediately after extubation, do not affect HRV. Interestingly, in an exploratory analysis, changes in HRV did occur during ns-NIV in the subgroup of infants who failed extubation. Hence, changes in HRV as early as $2 \mathrm{~h}$ after extubation should be further explored in larger studies as a potential predictor of postextubation respiratory failure. 


\section{HRV AND Respiratory SUPPORT IN PRETERM InfantS}

\section{REFERENCES}

1. SUPPORT Study Group of the Eunice Kennedy Shriver NICHD Neonatal Research Network. Early CPAP versus surfactant in extremely preterm infants. N Engl J Med 2010;362(21):1970-1979.

2. Morley CJ, Davis PG, Doyle LW, Brion LP, Hascoet J-M, Carlin JB. Nasal CPAP or intubation at birth for very preterm infants. N Engl J Med 2008;358(7):700-708.

3. Jensen EA, DeMauro SB, Kornhauser M, Aghai ZH, Greenspan JS, Dysart KC. Effects of multiple ventilation courses and duration of mechanical ventilation on respiratory outcomes in extremely lowbirth-weight infants. JAMA Pediatr 2015;169(11):1011-1017.

4. Walsh MC, Morris BH, Wrage LA, Vohr BR, Poole WK, Tyson JE, et al. Extremely low birthweight neonates with protracted ventilation: mortality and 18-month neurodevelopmental outcomes. J Pediatr 2005;146(6):798-804.

5. Miller JD, Carlo WA. Pulmonary complications of mechanical ventilation in neonates. Clin Perinatol 2008;35(1):273-281.

6. Al-Mandari H, Shalish W, Dempsey E, Keszler M, Davis PG, Sant'Anna G. International survey on periextubation practices in extremely preterm infants. Arch Dis Child Fetal Neonatal Ed 2015; 100(5):F428-F431.

7. Ferguson KN, Roberts CT, Manley BJ, Davis PG. Interventions to improve rates of successful extubation in preterm infants: a systematic review and meta-analysis. JAMA Pediatr 2017;171(2):165-174.

8. Lemyre B, Davis PG, De Paoli AG, Kirpalani H. Nasal intermittent positive pressure ventilation (NIPPV) versus nasal continuous positive airway pressure (nCPAP) for preterm neonates after extubation. Cochrane Database Syst Rev 2017;2:Cd003212.

9. Chang H-Y, Claure N, D’Ugard C, Torres J, Nwajei P, Bancalari E. Effects of synchronization during nasal ventilation in clinically stable preterm infants. Pediatr Res 2011;69(1):84-89.

10. Task Force of The European Society of Cardiology and The North American Society of Pacing and Electrophysiology. Heart rate variability: standards of measurement, physiological interpretation and clinical use. Circulation 1996;93(5):1043-1065.

11. Fairchild KD. Predictive monitoring for early detection of sepsis in neonatal ICU patients. Curr Opin Pediatr 2013;25(2):172-179.

12. Kaczmarek J, Chawla S, Marchica C, Dwaihy M, Grundy L, Sant'Anna GM. Heart rate variability and extubation readiness in extremely preterm infants. Neonatology 2013;104(1):42-48.

13. Goulding RM, Stevenson NJ, Murray DM, Livingstone V, Filan PM, Boylan GB. Heart rate variability in hypoxic ischemic encephalopathy during therapeutic hypothermia. Pediatr Res 2016;81(4):609615.

14. Massaro AN, Campbell HE, Metzler M, Al-Shargabi T, Wang Y, du Plessis A, Govindan RB. Effect of temperature on heart rate variability in neonatal ICU patients with hypoxic-ischemic encephalopathy. Pediatr Crit Care Med 2017;18(4):349-354.

15. Dargaville PA, Gerber A, Johansson S, De Paoli AG, Kamlin CO, Orsini F, Davis PG. Incidence and outcome of CPAP failure in preterm infants. Pediatrics 2016;138(1):e20153985.

16. Moretti C, Gizzi C, Papoff P, Lampariello S, Capoferri M, Calcagnini G, Bucci G. Comparing the effects of nasal synchronized inter- mittent positive pressure ventilation (nSIPPV) and nasal continuous positive airway pressure (nCPAP) after extubation in very low birth weight infants. Early Hum Dev 1999;56(2):167-177.

17. Kiciman NM, Andréasson B, Bernstein G, Mannino FL, Rich W, Henderson C, Heldt GP. Thoracoabdominal motion in newborns during ventilation delivered by endotracheal tube or nasal prongs. Pediatr Pulmonol 1998;25(3):175-181.

18. Kirpalani H, Millar D, Lemyre B, Yoder BA, Chiu A, Roberts RS A trial comparing noninvasive ventilation strategies in preterm infants. N Eng1 J Med 2013;369(7):611-620.

19. Kamath MV, Watanabe MA, Upton A. Heart rate variability (HRV) signal analysis: clinical applications. Boca Raton, Florida: CRC Press; 2012:203-299.

20. Looga R. Reflex cardiovascular responses to lung inflation: a review. Respir Physiol 1997;109(2):95-106.

21. Reis MS, Sampaio L, Lacerda D, De Oliveira L, Pereira GB, Pantoni $\mathrm{C}$, et al. Acute effects of different levels of continuous positive airway pressure on cardiac autonomic modulation in chronic heart failure and chronic obstructive pulmonary disease. Arch Med Sci 2010;6(5):719-727.

22. Pantoni CBF, Mendes RG, Thommazo LD, Catai AM, Sampaio LMM, Borghi-Silva A. Acute application of bilevel positive airway pressure influences the cardiac autonomic nervous system. Clinics 2009;64(11):1085-1092.

23. Borghi-Silva A, Reis MS, Mendes RG, Pantoni CBF, Simoes RP, Martins LEB, Catai AM. Noninvasive ventilation acutely modifies heart rate variability in chronic obstructive pulmonary disease patients. Respir Med 2008;102(8):1117-1123.

24. Owen L, Morley C, Davis P. Pressure variation during ventilator generated nasal intermittent positive pressure ventilation in preterm infants. Arch Dis Child Fetal Neonatal Ed 2010;95(5):F359-F364.

25. Owen L, Morley C, Dawson J, Davis P. Effects of non-synchronised nasal intermittent positive pressure ventilation on spontaneous breathing in preterm infants. Arch Dis Child Fetal Neonatal Ed 2011;96(6): F422-F428.

26. Moreau-Bussière F, Samson N, St-Hilaire M, Reix P, Lafond JR, Nsegbe É, Praud J-P. Laryngeal response to nasal ventilation in nonsedated newborn lambs. J Appl Physiol 2007;102(6):2149-2157.

27. Chang H-Y, Cheng K-S, Lung H-L, Li S-T, Lin C-Y, Lee H-C, et al. Hemodynamic effects of nasal intermittent positive pressure ventilation in preterm infants. Medicine 2016;95(6):e2780.

28. Sant'Anna GM, Keszler M. Weaning infants from mechanical ventilation. Clin Perinatol 2012;39(3):543-562.

29. Padhye NS, Williams AL, Khattak AZ, Lasky RE. Heart rate variability in response to pain stimulus in VLBW infants followed longitudinally during NICU stay. Dev Psychobiol 2009;51(8):638-649.

30. Khattak AZ, Padhye NS, Williams AL, Lasky RE, Moya FR, Verklan MT. Longitudinal assessment of heart rate variability in very low birth weight infants during their NICU stay. Early Hum Dev 2007; 83(6):361-366.

31. Shalish W, Rao S, Sant'Anna G, Mortola J. Breath-by-breath analysis of respiratory sinus arrhythmia in preterm infants [abstract]. Am J Respir Crit Care Med 2016;193:A3835. 